\title{
BOOK REVIEW: LIFELONG LEARNING IN EUROPE: NATIONAL PATTERNS AND CHALLENGES
}

\author{
EVE-LIIS ROOSMAA \\ TRIIN ROOSALU \\ ELLU SAAR
}

for Research

in Adult Education

From the point of view of adult education, contemporary research accounts on formal education and lifelong learning is somewhat eschewed. First line of discussion, concentrating on VET or higher education, often completely forgets or marginalises its nontaditional, adult students. The second strand of current research deals thoroughly with learning from the adults' point of view, but mostly considers nonformal and informal learning. To bridge this gap and pay long due attention to the nontraditional, adult students in formal education system, the editors of this book have followed the tradition opened by Shuetze and Slowey ${ }^{1}$, but looking at a different set of countries - such that to some extent could be claimed more similar to each other than the ones discussed in the 2000 volume. This book provides an illuminating account of the nature of contemporary lifelong learning (LLL) in Europe. The institutional and social context to lifelong learning, as well as path-dependency of its development, is the cornerstone of the approach the editors employ.

Leading scholars in the field already praise the book highly. Professor Rubenson from the University of British Columbia (Canada) claims this to be "a must read for policy makers, practitioners and academics", explaining that the book "provides an intriguing framework for how the variety in national systems of adult learning and their outcome can be addressed" and noting, that "the theoretical work is grounded in sophisticated national case studies that offer unique insights into why, or why not, a person embarks on adult learning”. Professor Bills from University of Iowa (USA) stresses, that "the volume is far more than a collection of isolated case studies, but is a tightly coherent and thematically unified piece of theoretical and empirical sociological work, and both researchers and policy makers will find much value in it".

So, what makes the book such a valuable contribution to the literature on lifelong learning? Based on prior cooperation by the authors who jointly carried out the research agenda within a European Union (EU) project that explored policy and practice in 13 European countries, the book covers next to established Western EU member states (Austria, Belgium, the United Kingdom, Ireland) a wide spectrum of newer EU member states of post-socialist Central and Eastern Europe (Bulgaria, the Czech Republic, Estonia, Hungary, Lithuania, Slovenia) as well as countries outside of EU (Norway, Russia). Different political, economic and cultural backgrounds of the participating countries have allowed the researchers to compare various concepts and practices of LLL adopted across the countries. As the research was carried out between 2005 and 2011, the chapters in this book are all based on up-to-date empirical investigations. Largely, the chapters address LLL policies, the participation of adults in formal learning, their access to learning, perceived obstacles to participation and perceived individual demand for learning opportunities. In addition to this, the book also studies the complex relationships between perspectives at the European level and the LLL policies and practices within European countries.

The book consists of two parts. Part I deals with conceptual considerations, profoundly revisiting and even

Edited by Ellu Saar (Tallinn University, Estonia), Odd Bjørn Ure (Fafo, Norway), John Holford (University of Nottingham, UK) Published in 2013 by Edward Elgar Publishing, 416 pp 
revising the concepts of adult education, as well as formal education and non-formal education. The notion of lifelong learning itself and the extent to which national education and training systems have embarked on LLL trajectories instead of only paying tribute to LLL slogans is discussed as a critical issue. First chapter investigates national LLL policies from the European perspective, in which the EU policy framework is at the centre. This topic is followed by exploring typologies of LLL systems stemming from welfare state, skill formation and varieties of capitalism theories. The authors claim that typologies help researchers and policy-makers to escape from assumptions of a single economic trajectory for market economies and for their LLL systems. As the constituting subsystems of LLL are analysed as societal fields in this book, the work of typologizing becomes more than a neat dissection of these fields into smaller parts. Instead, the efforts reflect transformations of Europe's educational systems. However, existing typologies need revision. The authors demonstrate this by particularly looking into post-socialist countries, where the structural and public policy frameworks can only be captured by more finely tuned analytical tools, such as the additional distinction 'dependent market economies'. The last chapter in Part I proposes a novel comparative framework of formal adult education based on a typology particularly emphasizing the composition of the organizational populations providing formal adult education. This composition encompasses organizations belonging to different organizational fields, notably liberal adult education, management training, trade unions and initial vocational education. The proposed framework partly builds on observations accruing from the Eurostat Adult Education Survey carried out at a national and cross-national level.

The notion of organizational fields is then applied to the Austrian educational system in one of the 12 country chapters that constitutes the Part II of the book, where the national experts sum up key findings from their domestic research carried out during the five-year period. Chapter on Austria offers a new typology of formal learning focusing on the adult population. Considering the diversification of formal education into seven organizational fields, varying from basic skills programmes to continuing professional training, the authors call for transgression of traditional 'demarcation lines', allowing to take account of formal adult education, non-formal firm-based training, liberal and civic adult education. The chapter highlights the social acceptance of educational programmes and their resulting qualifications, instead of the traditional approach of grouping actors along institutional similarities or grouping of qualifications along types of programmes.

This triad of learning - formal, non-formal and informal - is firmly established in EU since the mid- 1970s. According to some perspectives, elements from formal, non-formal and informal education should be synthesized and strong links developed between them, in order for systems of lifelong education to evolve. In line with this, chapter on Ireland makes the theoretical point that LLL should encompass both socio-personal and institutional processes. One approach is to forge links between the sectors of community education, formal education and training in order to enable individuals who have experienced educational disadvantage to continue their studies. The institutional form of such non-formal education could be community LLL centres. Theoretically, community LLL centres represent what the Irish researchers call 'community capital' - combination of cultural and social capital embodying collective resources for the entire community - that brings us back to the human capital versus social capital perspective set forth above. However, analysis of Russian context indicates that non-formal and informal learning there is basically split from the further education system. Non-formal learning experiences are not recognized by formal education institutions and the Russian government hesitates to strengthen the legal basis of adult education. There is thus a clear need for moving towards building bridges between the formal and non-formal learning settings. However, analysis on Flanders (in Belgium) warns that nonformal education per se is not a solution for social inclusion in adult education, as vulnerable groups of learners participate less in non-formal compared to formal learning. The traditional inequalities in participation by gender, age, citizenship, labour market status and level of education are stronger in non-formal than in formal education.

As in EU policies, though, the analyses reveal general trend across the countries of lifelong learning policies focusing on labour market issues. Several authors report biased policies because LLL is predominantly following a narrow employability agenda. In Scotland, two perspectives on LLL - economic competitiveness and growth versus social cohesion and inclusion were investigated by looking into the LLL discourse from the angle of social inclusion. The authors point out that the discourses they observed - redistribution, moral underclass and social integration - are not mutually exclusive: the redistribution of the opportunity to participate in learning may, for example, enable a socially marginalised individual to achieve a qualification for entry into the labour market.

A number of chapters analyse the interaction between structural factors and individuals' dispositions in the field of LLL, providing insight into agency mechanisms. We learn for example how various actors (e.g. interest groups) promote or resist transformations of education and training systems, possibly in the direction of an emerging national framework for LLL. 
This process in Norway leads to educational practices gradually forming patterns pointing towards the existence of building blocks of a LLL system, and the chapter demonstrates that institutional strategies do matter. Path-dependency and institutional agency are also discussed in chapters on Estonia and Bulgaria.

Some contributions touch upon policy learning exercise of LLL strategies. In case of Slovenia, the authors argue that already during the accession period before becoming an EU member the country benefited from EU policies in the field of lifelong learning and employment: good practices from other countries contributed to the development of more coherent systems, which facilitated participation in formal and non-formal adult education. Still, LLL in Slovenia is understood narrowly as education of adults predominantly in the non-formal settings. Bulgaria in turn was extremely sensitive to all initiatives coming from international and especially European organizations after the accession to EU in 2007, so that the assimilation of these initiatives has often assumed the character of borrowing, imitation and copying. This way, certain elements quite distant in nature from Bulgarian post-communist reality were introduced and artificially implanted, thereby generating distorted and rather ineffective social practices. Chapter on Lithuania looks back even further, at the first years after independence from the Soviet system, and concludes that the education system evolved from a highly ideological and domestic to a more open internationalizing' system. Researchers conclude that the efforts to improve participation in LLL have so far proven to be insufficient, mainly because too little importance is attached to adults' access to higher education.
Looking into the need to consider post-Soviet typologies of LLL separately from the post-socialist ones was one of the aims of the book. The chapter on Estonia points out the country's post-socialist dedevelopment originating from the dissolution of the socialist system as well as the Soviet state that lead to some disregard towards its thoroughly designed educational institutions. The authors claim that there's the utmost time to pay attention to the fact that the country is not just catching up the EU15 but also to its own past, at least as far as the culture of education and training goes. The chapter on Russia further investigates the Soviet heritage, explaining how the formal education system in Russia remained a direct product of the Soviet system and is thus rather unable to adapt to and meet the demands of the nascent capitalist labour market. The Russian experts maintain that the largest obstacle in bridging the gap between the formal education system and the labour market is the inability to effectively use the positive heritage of the Soviet education system. It may be suggested there's a need to further compare current EU ideologies on education and training with the former USSR ones. By bringing in these approaches, the book joins the emerging strand in the studies of post-socialism, breaking through the merely negative representation of post-socialist or post-Soviet experience by indicating the LLL favouring aspects of the former regime.

The varied perspectives taken by the authors in the book, presented in a coherent yet innovative analytical framework provided by the team of editors, make the volume a valuable resource for the practitioners, policymakers as well as students and researchers in the field of lifelong learning. 